time traversing it with the shot stream. It is being used in a fundamental study of the effects of shotpeening and optimization of it, together with an assessment of possible methods of measuring intensity.

The first floor is devoted to light laboratories (containing small static testing machines, general scientific instruments and equipment), administrative offices, and a conference room. The materials testing laboratory contains machines for determining macrohardness, tensile and torsional properties of wires and load-deflexion characteristics of small springs. Metallographic facilitios are provided in specially fitted rooms for rough sample preparation, fine polishing and etching, microseopical examination and photography. The microseope room contains a highpowered binocular bench microscope, projection mieroscope and micro-hardness testing equipment.

The Organisation is studying spring materials for elevated temperature applications, in particular the stress-temperature relaxation properties of springs made from a very wide range of alloys. A battery of spring creep testing machines is installed which will enable the behaviour of springs to be determined up to $850^{\circ} \mathrm{C}$.

\title{
CHEMISTRY OF PROPELLANTS
}

\begin{abstract}
A MEeting was recently held in Paris (June A 8-12) under the auspices of the Combustion and Propulsion Panel of the Advisory Group for Aeronautical Research and Development, with "Chemistry of Propellants" as the main topic. It was felt that such a meeting could contribute to a useful exchange of research information and discussion of eurrent problems among North Atlantic Treaty Organization countries. Its importance can be judged by the attendance of nearly two hundred observers from eleven countries, nominated through their Advisory Group for Aeronautical Research and Development national delegates.
\end{abstract}

The meeting was opened by Dr. von Karman, who was supported by Dr. Seitz, the science adviser to the North Atlantie Council, and his recent predecessor, Dr. N. F. Ramsey. Later in the week Dr. G. B. Kistiakowsky, the new scientific adviser to the President of the United States, attended and took part in the proceedings. These could be classified under three main headings, namely, propellants or associated features for liquid rockets, solid rockets and air-breathing engines, and the papers presented covered reviews of existing knowledge, reports of recent work and assessments of future problems.

The first technical session was introduced by a paper by S. Greenfield (United States), who reported on an experimental evaluation of liquid-propellant, data. This was based on a research programme to compare differences in behaviour of various hydro. carbon fuels when burned with liquid oxygen. The fuels were pure samples of each of the chemical types such as paraffins, aromatics and olefins together with a reference fuel specified as $J P-5$. The main results covered liquid film heat transfer coefficients and their variation with heat flux and combustion stability, specific impulse variations with mixture ratio, and effect of aromatics on available energy in fuel-rich gases suitable for turbo-pump operation. An interesting feature of this work was the precise measurements achieved and the important influence of combustion chamber length (or $L^{*}$ ) on performance. The conclusion was drawn that naphthenics are beneficial in a mixed fuel, but normal paraffins are of doubtful value.

This paper was, to some extent, complementary to another by R. J. Thompson (United States) covering theoretical performance evaluation. This work was carried out on an electronic data-processing machine and presented a vast tabulation of thermodynamic functions and propellant parameters which were discussed and illustrated. The main propellant com- bination discussed was liquid oxygen and kerosene, although data on fluorine-liquid hydrogen were also used to illustrate the calculations. Additionally, thermodynamic properties as functions of temperature for eleven of the more important elementary monatomic gases were given. It is certain that these two papers will be of great use in future studies of propellants.

The next paper in this group was by D. L. Arm. strong (United States) and reviewed the characteristics of liquid propellants desired and achieved in rocket engines. The important physical properties included vapour pressure, density, viscosity, specific heat, boiling and freezing points, and other features which were tabulated and discussed. Chemical properties were also enumerated and mention was made of reactivity, self-ignition, combustion kinetics, stability and corrosion. The author also gave some indication of performance, manufacturing processes and suggested propellants for various missions, but much more detailed and relevant papers on these aspects were presented by W. G. Parker and G. Ruston (Great Britain) on the merits of utilizing highenergy propellants, and S. H. Dole and M. A. Margolis (United States) on the sourees, availability and estimated cost of propellants. The former took a slightly unusual line in dismissing the majority of the exotic propellants from consideration, first, because of the unfavourable properties such as extreme reactivity and toxicity, and secondly, because the advantages of higher specific impulse become less marked beyond values of about $320 \mathrm{sec}$. Their conclusions were that liquid hydrogen was worth develop. ing because of its probable use in nuclear rockets, but it should be in combination with nitric acid or hydrogen peroxide rather than liquid oxygen. The accidental combination of hydrogen and oxygen liquid or vapour could be too great a hazard to risk. The paper on costs pointed out that prices of many propellants would be significantly altered if production demands increased, but even allowing for this, it was clear that the cryogenics would give a better performance than the storable liquids for a given cost. Costs should, however, include the overall system cost, and some curves were given showing flight vehicle cost against total impulse required for solid propellant, storable and cryogenic. At the higher values of total impulse, the cost of using these propellants was in descending order. This was strongly challenged by protagonists of solid propellants during the discussion.

The papers on solid propellants were given by R. Steinberger (United States) on the properties of 
double-base forms with a corresponding one by P. Tavernier and J. Boisson (France) on composite forms and one on burning rate control by G. H. Young (Great Britain). All these appeared to suffer from the limitations imposed by 'security', but the first two gave useful accounts of the standard materials and processes in manufacture. It was interesting to compare these and from this point of view they were an informative contribution. Steinberger, howover, included a good deal more on the life expectancy of double-base propellants. This is not surprising in view of the much longer experience of them which exists. The paper by Young covered some of the same ground and, rather than a discussion of burning rate control, was limited to descriptions of methods of measuring burning rate and the range of burning rates achieved. The difficulties imposed on this author by the classified nature of his subject were obvious and it was generally agreed that it could only receive suitable treatment at a closed session.

The papers on air-burning fuels included one on properties and preparation of ramjet fuels by M. Barrere and G. Français (France), one on performance evaluation by $\mathrm{E}$. Porchonok (United States), one on deposits in jet engines by $R$. Breit wieser (United States) and a final one on physicochemical reactions during nozzle flow by J. F. Morris (United States). The first two covered the main features found necessary in the special conditions of ramjet operation and collected much data which will be useful for future reference. Both papers dwelt on the use of solid fuels in slurry form and the attractions of boron hydrides and other compounds, but the American paper emphasized some additional considerations if ramjets are to be operated at hypersonic speeds. For example, the need for regenerative cooling of engine walls will limit the use of $J P-4$ fuel to speeds of $M=6$. The high gas temperatures resulting from these speeds also have an important effect on dissociation conditions and thrust available. With frozen gas exit flow, the thrust may be reduced as much as 58 per cent at $M=8$, compared with equilibrium flow. This problem was treated by Morris, who reviewed the background of relaxation rate-theory and discussed the gaps in knowledge which will enable predictions of non-equilibrium flow of both internal and external gas for hypersonic vehicles. The long list of references appended to this paper calls for special mention as it extends to more than four hundred. The other paper in this group emphasized the problems of solid deposits in engines and pointed out that these became more serious with some of the high-energy fuels now being considered. Boric oxide is one combustion product which may form on engine surfaces in large quantities. Some measurements on convergent-divergont nozzles showed losses in total stream momentum of more than 5 per cent within 20 sec. of initiating combustion. Other sensitive components are turbine stator blades and combustion chambers. Two mechanisms of deposition were discussed, consisting of diffusion of particles less than $\frac{1}{2} \mu$ diameter, and of impact by particles of $5 \mu$ and larger. The former was analysed theoretically and compared with measured deposition rates. Although good agreement was claimed, this analysis received some criticism during the discussion.

In addition to the papers, a round table discussion on basic problems in propulsion was held with Dr. von Karman in the chair. The discussion was initiated by A. D. Baxter (Great Britain), who summarized the merits of liquid propellant rocket engines and outlined some of the remaining lines which require research. These included physical problems such as heat transfer and combustion chamber design parameters, and chemical problems associated with propellant stability, ignition delays and reaction rates. H. W. Ritchey (United States) then presented a similar case for solid propellants and was followed by three speakers giving views on futuristic possibilities. G. B. Kistiakowsky (United States) spoke on solid propellant horizons, J. W. Bond (United States) on electromagnetic and nuclear thermal propulsion, and A. Ferri (United States) on composite launchers. The last was a stimulating argument in favour of air breathing engines as the first stage in multi-stage rocket vehicles. One of the advantages would be the ability to fit aerodynamic lifting surfaces and fly the launcher back to the take-off point. The discussion was so successful that it was continued at the final session of the meeting, ranging over a broad field. Points brought out were the convergence of design features in solid-and liquid-propellant engines, the question as to how vital improved specifie impulse was, the problems of size in rockets and the future of nuclear rockets.

This discussion was a fitting climax to a successful meeting and no doubt, when the edited proceedings are published, they will be found to provide a valuable addition to the literature, not only because of the data included, but equally because of the excellent bibliographies attached to most papers. A. D. BAXTER

\section{CLAY MINERALS}

T TWO series of meetings on clay minerals were held in Yorkshire during April. The first, at Shefficld, was arranged by the Clay Minerals Group of the Mineralogical Society. Two sessions on April 15, in the Metallurgy Department of the University, were devoted to the reading of scientific papers, while on April 16 visits were made to the works of Thomas Marshall at Loxley and General Refractories at Wharncliffe. The chair at the scientific sessions was occupied by Dr. A. F. Hallimond (London), chairman of the Group, in the morning, and by Prof. J. White (Sheffield) in the afternoon.

Several papers concerned the industrial application of clay mineralogy. In the first of these, E. $H$.
Steger (London) discussed various problems in civil engineering in which clays are implicated, and dealt particularly with soil stabilization by injection of a suitable clay suspension into sands, etc. The factors necessary to give good results are broadly known, but much work on fundamental aspects is still required. In the discussion, the difficulty of replicating laboratory findings in the field was widely referred to.

Divergent views upon the relationship between the mineralogical constitution and the firing properties of clays were expressed by Prof. G. W. Brindley and S. Udagawa (Pennsylvania) and by Dr. R. W. Nurse (Watford). The former described how, by 'synthesizing' clays from mixtures of appropriate pure 